\section{Tejido prostático en teratoma quístico maduro del ovario. Caso clínico}

\author{
PABLO GUZMÁN G. ${ }^{1}$, DOUGLAS GRAF C. ${ }^{2}$
}

\section{Prostatic tissue in a mature cystic teratoma of the ovary. Report of one case}

Male accessory sexual glands arising in ovarian cystic teratoma are exceedingly rare. We report a 56-year-old female subjected to an ovariohysterectomy due to a left ovarian mass. The pathological study of the surgical piece revealed a tumor composed of different mature tissue elements and well defined nodules of benign prostatic tissue.

(Rev Med Chile 2012; 140: 93-97).

Key words: Ovarian neoplasms; Prostatic neoplasms; Teratoma, cystic.

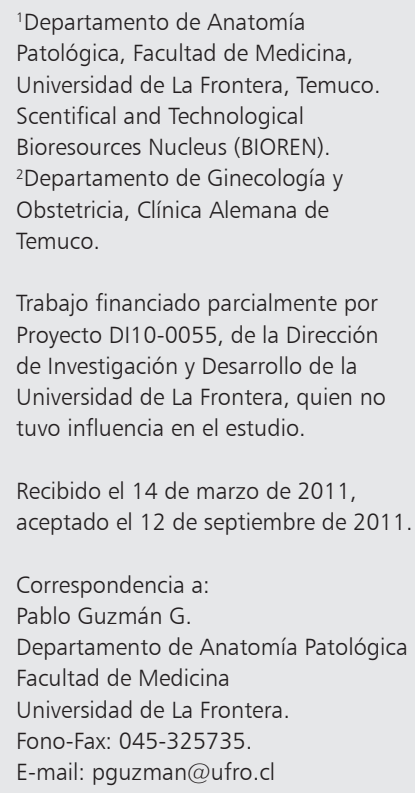

Trabajo financiado parcialmente por Proyecto DI10-0055, de la Dirección de Investigación y Desarrollo de la Universidad de La Frontera, quien no tuvo influencia en el estudio.

Recibido el 14 de marzo de 2011, aceptado el 12 de septiembre de 2011.

Correspondencia a: Pablo Guzmán G.

Departamento de Anatomía Patológica Facultad de Medicina

Universidad de La Frontera. Fono-Fax: 045-325735.

E-mail:pguzman@ufro.cl

$\mathrm{E}$ 1 teratoma quístico maduro del ovario es un tumor quístico compuesto por tejidos bien diferenciados, derivados de las tres capas germinativas (endodermo, mesodermo y ectodermo $)^{1}$. Es el tumor benigno de células germinales más frecuente en mujeres en edad reproductiva. La mayoría de los casos son unilaterales ${ }^{2}$. Posee un patrón cromosómico 46,XX y surge por partenogénesis de una célula ovárica germinal única, posterior a la primera división meiótica ${ }^{3}$. La gran variedad de tejidos maduros que lo componen, le otorga características particulares macroscópicas e histológicas, por lo que resulta bastante fácil de diagnosticar en la evaluación patológica de rutina. A pesar de la gran diversidad microscópica de esta lesión, incluso con sus respectivas contrapartes malignas $^{4}$, resulta sorprendente el hallazgo de tejido prostático en ausencia de un cromosoma Y, necesario para la diferenciación sexual masculina. Se presenta un nuevo caso de este fenómeno rara vez descrito, junto a revisión de la literatura y principales teorías patogénicas.

\section{Caso clínico}

Mujer de 56 años, fenotípicamente normal, sin evidencias de virilización ni endocrinopatías, multípara de un hijo por parto normal, que consultó por prolapso genital leve. En el chequeo de rutina anual, se pesquisó lesión ovárica izquierda de $2 \mathrm{~cm}$ de diámetro con áreas ecogénicas en su interior, al ultrasonido. Se realizó histerectomía y anexectomía bilateral, con evolución postoperatoria satisfactoria.

\section{Preparacion de la muestra}

La pieza quirúrgica fue fijada en formalina neutra tamponada al 10\%. Las muestras representativas obtenidas se incluyeron en parafina para el procesamiento histológico y fueron teñidas con hematoxilina-eosina (H-E). Para análisis inmunohistoquímico se seleccionaron y cortaron inclusiones de tejido en parafina. Con la técnica de complejo avidin-biotina, se realizaron las siguientes inmunotinciones: antígeno prostático específico (PSA, clon ER-PR8 +PA05, 1:100, Neomarkers), fosfatasa ácida prostática (PAP, policlonal, 1:100,

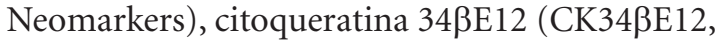
1:50, BioSB) y citoqueratina 7 (CK7, clon OV-TL, 1:75, Dako). Como cromógeno se utilizó diamenobenzidina. Los núcleos se contrastaron con hematoxilina.

Para la revisión de la literatura se efectuó búsqueda y selección de artículos bibliográficos, en inglés y español, desde MEDLINE usando tér- 
minos libres y MESH, entre otros: teratoma, ovary, prostate. Un número extra de publicaciones se obtuvo de las referencias de los artículos previamente seleccionados, también mediante la función " $r e$ lated papers" en MEDLINE y búsquedas dirigidas en tablas de contenido de revistas especializadas de patología, oncología y ginecología. La selección bibliográfica incluyó mayoritariamente artículos en inglés o español, con texto en extenso o resumen completo.

\section{Resultados}

\section{Anatomo patológicos}

En el examen macroscópico, útero y anexo derecho, de estructura conservada, no se identificaron lesiones. El ovario izquierdo de $2,5 \mathrm{~cm}$, incluía lesión sólido-quística unilocular de $2 \mathrm{~cm}$, rellena por material mucoídeo, blanquecino.

Histológicamente, el componente sólido contenía estructuras bien diferenciadas, que incluían tejido fibroconectivo, muscular liso, óseo, adiposo, glándulas de tipo salival y epitelio respiratorio. El quiste estaba revestido por epitelio cilíndrico mucosecretor, ciliado y urotelio. Un nódulo bien delimitado, no encapsulado, de $5 \mathrm{~mm}$, que hacia prominencia hacia el lumen, estaba constituído por glándulas separadas por estroma fibromuscular liso, que esbozaban patrón lobular, con acinos de tipo prostático de tamaño mediano, revestido por células cúbicas y cilíndricas de citoplasma pálido, con células basales ocasionales. En la inmediata vecindad se identificó revestimiento urotelial y estructuras que recordaban el seno urogenital (Figura 1). No se encontró tejido testicular ni células luteinizadas en tejido ovárico vecino.

Los marcadores inmunohistoquímicos específicos para tejido prostático (PSA y PAP) reaccionaron positivamente en las glándulas prostáticas, con refuerzo hacia apical y no tiñeron el urotelio. Las citoqueratinas reaccionaron en epitelio glandular prostatico sólo a nivel basal (mioepitelio). La CK 7 también resultó positiva en urotelio y la CK $34 \beta E 12$ reaccionó en las células uroteliales basales (Figura 2). Este patrón de tinción es igual al esperado para glándula prostática normal.

\section{Discusión}

El hallazgo de tejido prostático en un teratoma quístico maduro del ovario es poco frecuente, sin embargo, podría estar subdimensionado ya que, Vadmal y cols ${ }^{5}$ después de un examen y muestreo cuidadoso de la lesión, encontraron glándulas prostáticas hasta en $12 \%$ de los teratomas ováricos y otros autores reconocen confusión con otras glándulas como las sudoríparas ${ }^{6}$.

La Tabla 1 resume la veintena de publicaciones en la literatura internacional, la mayoría de ellos se descubren en mujeres en edad fértil (edad promedio 35 años y rango 15-73 años), generalmente como hallazgo en el estudio de dolor o masa pélvica. Fue más frecuente en teratomas que afectaban al ovario izquierdo, que promediaban 7,3 $\mathrm{cm}$ y 153 g. El tamaño promedio de los focos glandulares prostáticos que se han publicado es de $1,2 \mathrm{~cm}$ y en el cual, algunos autores incluso han reportado neoplasia in situ ${ }^{19}$ y adenocarcinoma invasor ${ }^{6}$, transformando así, un hallazgo interesante, en un fenómeno clínicamente significativo.

La tinción inmunohistoquímica mostró en las glándulas prostáticas de nuestro caso, reacción intensa y uniforme en todo el epitelio glandular, para PSA y PAP, al igual que en tejido prostático normal. Esto resulta relevante ya que el diagnóstico diferencial, incluye a la glándula de Skene o parauretral femenina, considerada como la equivalente en la mujer de la próstata y la cual presenta una positividad multifocal e irregular para esos anticuerpos ${ }^{21}$.

El desarrollo de un tejido masculino, como la próstata, en un teratoma ovárico es un fenómeno no totalmente aclarado. De la embriología se sabe que el desarrollo prostático es dependiente de la dihidrotestosterona, secretada dentro del seno urogenital. La presencia de urotelio en nuestro caso y en otros, apoya una de las tres teorías que se han propuesto, que apunta hacia una anormalidad del desarrollo ${ }^{6}$ y expresa que este epitelio y el tejido prostático en teratomas, surge de remanentes embrionarios de brotes endodérmicos del seno urogenital, estimulado por andrógenos locales producidos por células luteinizadas vecinas al teratoma y que se han encontrado en cuatro casos $^{6-8,13}$.

Una segunda teoría, basándose en hallazgos de tejido prostático en ovario, cuello uterino y vagina que surgen de remanentes mesonéfricos, plantea una explicación exclusivamente metaplásica a este fenómeno, también estímulado por un microambiente androgénico ${ }^{6,22}$.

Finalmente, se ha postulado también que en ausencia de identificación de fuentes producto- 
ras de andrógenos, hecho frecuente, la génesis de tejido prostático en una neoplasia de cariotipo $46 \mathrm{XX}$, surge por un fenómeno llamado impresión genómica específica tisular, en el cual la expresión específica tisular de cada par de alelos o cromosomas homólogos esta gobernada por el sexo del progenitor que trasmite esa región del genoma, y se expresaría en un tumor generado por partenogénesis, como el teratoma, donde no se inactivarían los genes paternos ${ }^{23}$.

En resumen, la presencia de tejido prostático en teratomas ováricos es un hallazgo interesante e infrecuente, aunque clínicamente poco relevante excepto cuando, de manera excepcional, se asocia a una neoplasia intraepitelial o adenocarcinoma prostático. Un examen y muestreo poco cuidadoso de los teratomas podría estar fomentando esta rareza.

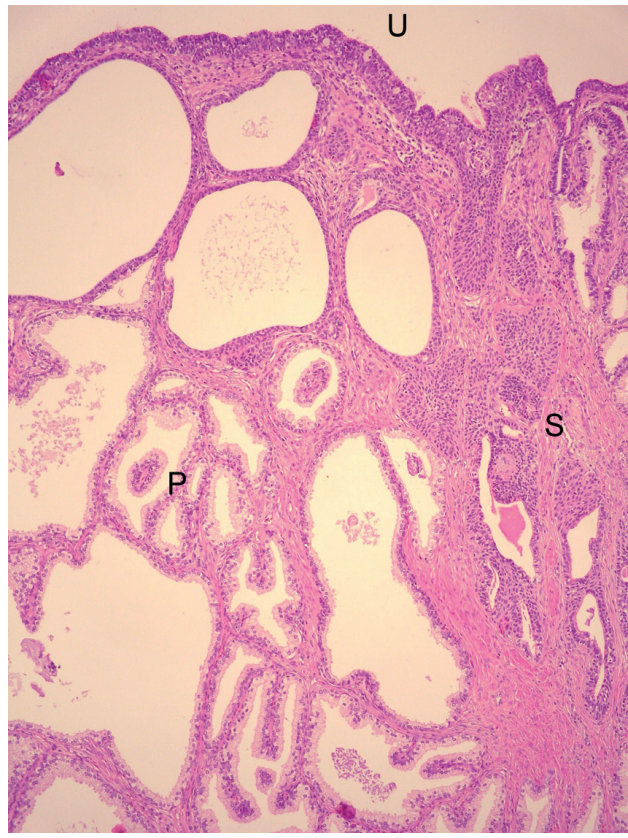

Figura 1. Parte del teratoma ovárico con tejido prostático $(P)$, revestimiento urotelial $(U)$ y zona que se asemeja al seno urogenital (S) (H-E, 100x).
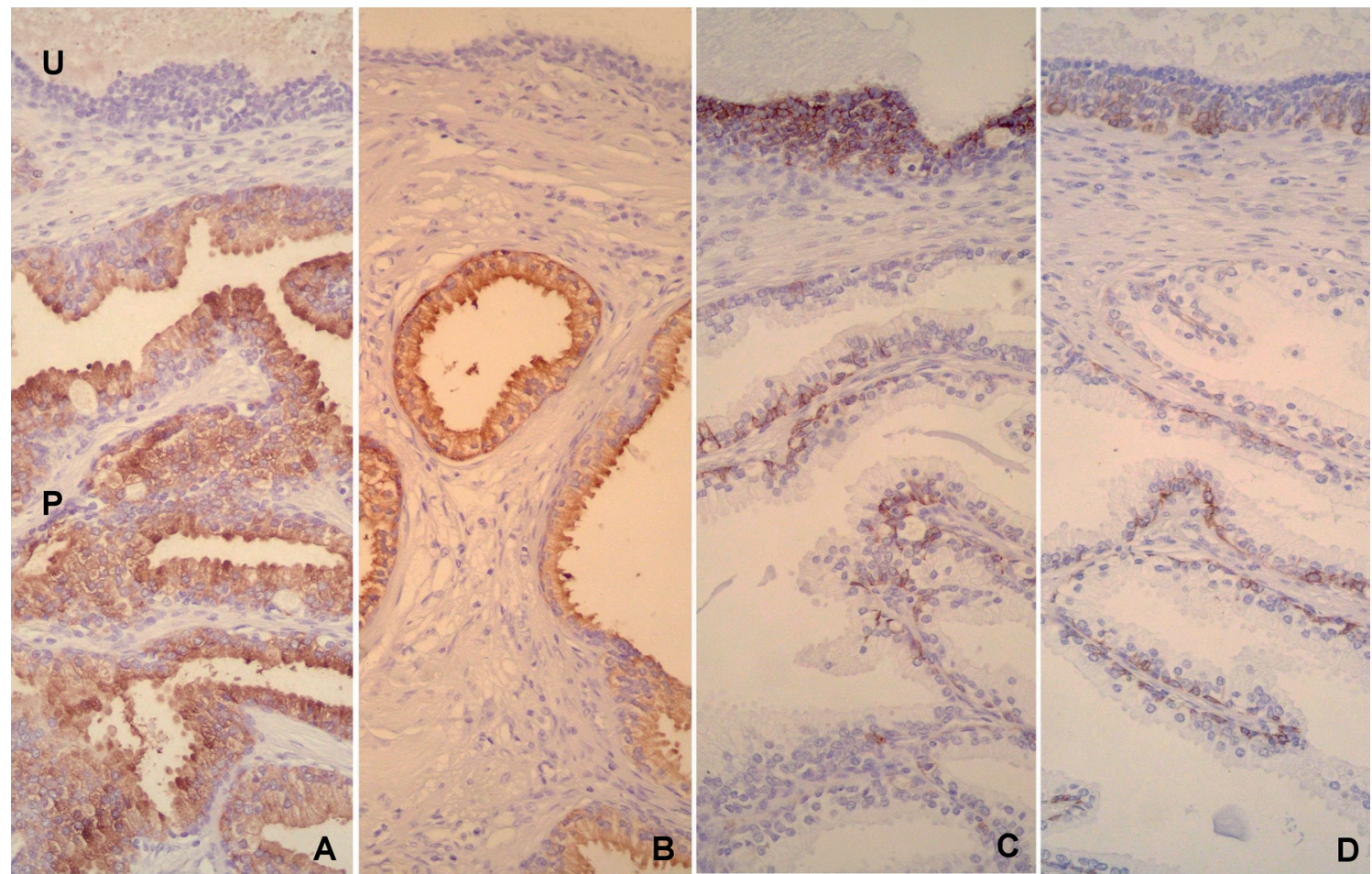

Figura 2. Tejido glandular prostático $(P)$ con inmunopositividad en células glandulares para PSA, PAP y sólo en mioepitelio para CK7 y CK34ßE12. El revestimiento urotelial (U) reaccionó con CK7 y sólo a nivel basal para CK34ßE12 (A: PSA, B: PAP, C: CK7 y D: CK34ßE12; 400x). 


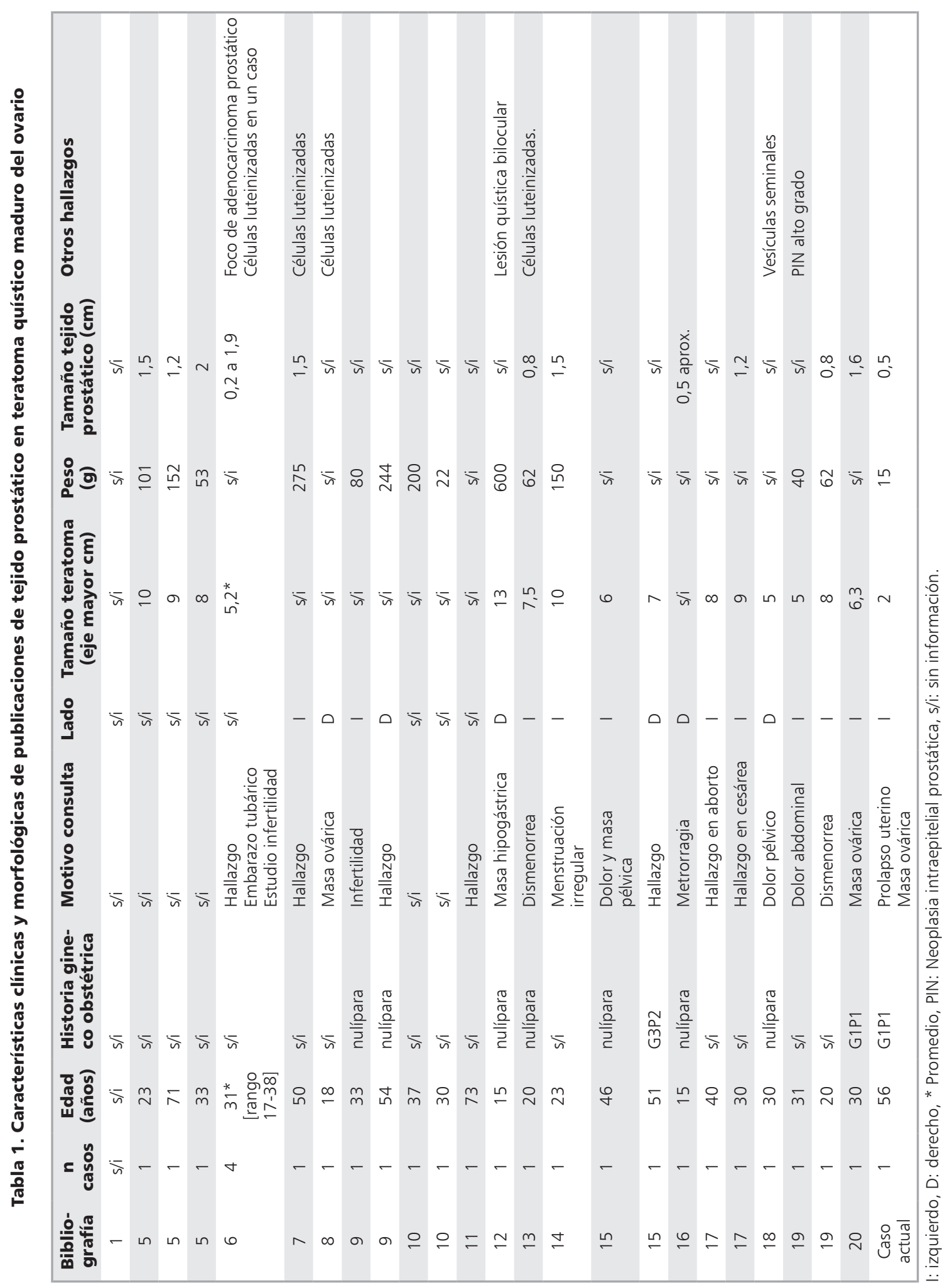




\section{Referencias}

1. Blackwell WJ, Dockerty MB, Masson JC, Mussey RD. Dermoid cysts of the ovary. Their clinical and pathological significance. Am J Obstet Gynecol 1946; 51: 151-72.

2. Koonings P, Campbell K, Mishell D, Grimes D. Relative frequency of primary ovarian neoplasms: a 10-year review. Obstet Gynecol 1989; 74: 921-6.

3. Linder D, McCaw BK, Hecht F. Parthenogenic origin of benign ovarian teratomas. N Engl J Med 1975; 292 (2): 63-6.

4. Sakuma M, Otsuki T, Yoshinaga K, Utsunomiya H, Nagase S, Takano T, et al. Malignant transformation arising from mature cystic teratoma of the ovary: a retrospective study of 20 cases. Int J Gynecol Cancer 2010; 20 (5): 76671.

5. Vadmal M, Hajdu SI. Prostatic tissue in benign cystic ovarian teratomas. Hum Pathol 1996; 27 (4): 428-9.

6. Halabi M, Oliva E, Mazal PR, Breitenecker G, Young RH. Prostatic tissue in mature cystic teratomas of the ovary: a report of four cases, including one with features of prostatic adenocarcinoma, and cytogenetic studies. Int J Gynecol Pathol 2002; 21 (3): 261-7.

7. Melniker LA, Slavutin LJ. Prostatic tissue in a benign cystic teratoma of the ovary. Diagn Gynecol Obstet 1980; 2 (2): 139-45.

8. Brumback R, Brown B, di Sant'Agnese PA. Unique finding of prostatic tissue in a benign cystic ovarian teratoma. Arch Pathol Lab Med 1985; 109 (7): 675-7.

9. McLachlin CM, Srigley JR. Prostatic tissue in mature cystic teratomas of the ovary. Am J Surg Pathol 1992; 16 (8): 780-4.

10. Uzoaru I, Akang EE, Aghadiuno PU, Nadimpalli VR. Benign cystic ovarian teratomas with prostatic tissue: a report of two cases. Teratology 1992; 45 (3): 235-9.

11. Buzzi A, Crescini C, Sonzogni A, Pezzica E. Prostatic tissue in a cystic teratoma of the ovary. Minerva Ginecol 1994; 46 (1-2): 49-51.

12. Nogales FF, Vergara E, Medina MT. Prostate in ovarian mature cystic teratoma. Histopathology 1995; 26 (4):
373-5.

13. Claros-González I, Arguelles-Fernández J, Triviño-López A, Camblor-Alonso L, Sáenz de Santamaría-Gutiérrez I, González-Martínez C. Próstata en teratoma maduro de ovario. Rev Esp Patol 1999; 32: 217-20.

14. Hong S, Choe M, Han E, Lee H, Ro J. Prostatic tissue in ovarian mature cystic teratoma. A case report. Korean J Pathol 1999; 33: 525-8.

15. Vlodavsky E, Kerner H. Prostatic tissue in a benign cystic teratoma of the ovary. Report of two cases. Isr Med Assoc J 2000; 2 (10): 783-4.

16. Cserni G, Tarján M. Prostatic tissue in a dermoid cyst of the ovary. Orv Hetil 2000; 141 (7): 355-6.

17. Resta L, Marzullo A, Pellegrino M, Rizzi E, Piscitelli D. Male urogenital sinus structures in mature cystic teratomas of the ovary. Report of two cases. Histopathology 2004; 45 (3): 303-5.

18. Shelekhova KV, Hejda V, Kazakov DV. Mature cystic teratoma of the ovary with male accessory sexual glands including seminal vesicles, prostatic tissue, and bulbourethral glands: a case report. Virchows Arch 2008; 452 (1): 109-11.

19. López JI, de Santamaría IS, Claros IJ, Garmendia M, Gaafar A, Bilbao FJ. Prostatic remnants in mature cystic teratoma of the ovary. Ann Diagn Pathol 2008; 12 (5): 378-80.

20. Na Rae Kim, Hyun Yee C, Dong Hae C, Kwang Beom L. Grossly visible prostatic tissue in an ovarian mature cystic teratoma: A case report. Basic and Applied Pathology 2010; 3: 31-33.

21. Tepper SL, Jagirdar J, Heath D, Geller SA. Homology between the female paraurethral (Skene's) glands and the prostate. Immunohistochemical demonstration. Arch Pathol Lab Med 1984; 108 (5): 423-5.

22. Nucci MR, Ferry JA, Young RH. Ectopic prostatic tissue in the uterine cervix: a report of four cases and review of ectopic prostatic tissue. Am J Surg Pathol 2000; 24 (9): 1224-30.

23. Graham CF. Strife in the germ line. Int J Dev Biol 1993; 37 (1): 25-31. 